\title{
MARIO TORRIOLI
}

\section{In Memoriam}

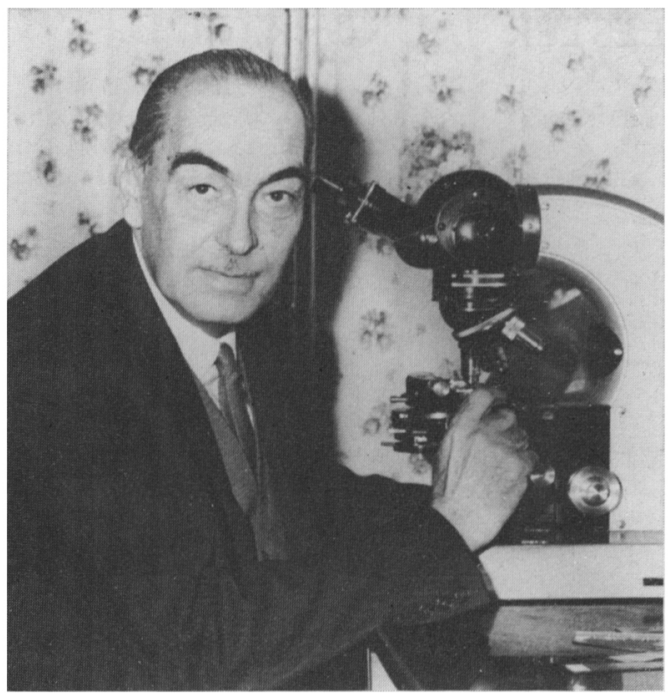

Ė con molto dolore che ricordiamo la morte del nostro Collaboratore, Prof. Mario Torrioli, avvenuta in Roma il 23 luglio 1974.

Fu allievo della Scuola Medica Romana e cioè di Ascoli e successivamente di Frugoni; Libero Docente di Patologia Speciale Medica e di Clinica Medica Generale; Direttore dei Laboratori di Biologia Sperimentale e poi Primario Medico presso l'Istituto del Cancro di Roma.

Fece parte della Delegazione Italiana presso l'OMS. Socio della Società Italiana e della Società Internazionale di Ematologia; socio onorario della Società di Ematologia Svizzera.

Approfondi, portando validi contributi, gli ipersplenismi prima, poi l'anemia perniciosa, per cui, nel' 45 , creò e diresse un Centro per l'assistenza agli emopatici sotto il patronato della Pontificia Commissione Assistenza.

Facendo parte dall'inizio del Comitato Editoriale della nostra rivista e a seguito della fondazione dell'Istituto Mendel, prese parte attiva alla scuola italiana di genetica medica, impegnandosi particolarmente nello studio dell'ereditarietà dell'anemia perniciosa.

Inoltre, presso l'Istituto Mendel egli sviluppò gli studi sulle malattie leucemiche che aveva iniziato in Clinica Medica e continuato all'Istituto Superiore di Sanità, dimostrando: 1) la trasmissibilità in serie su embrioni di pollo, e da questi al pollo adulto, dell'agente morboso della leucemia umana; 2) l'inattivazione al calore di tale agente patogeno; 3) la filtrabilità su Seitz; 4) la reazione allergica specifica di soggetti leucemici all'inoculazione sottocutanea di poltiglia di embrione di pollo inoculato con materiale leucemico umano, preventivamente inattivato e filtrato; 5) la presenza di particelle virali nell'embrione di pollo inoculato con sangue leucemico umano, fotografate al microscopio elettronico.

Commemorato nell'Aula Magna dell'Istituto Mendel il 21 novembre 1974, Mario Torrioli rimane nella storia della nostra Rivista, lasciando la memoria di un valoroso ricercatore e di un prezioso amico.

\section{LUIGI GeDDA}

Acta Genet. Med. Gemellol. (1975), 24: 186 